\title{
Optimization of the Production Process of an A-Pillar using a Differential Thickness Profile Approach via FEA
}

\author{
By Nicolas Saba* \\ Jihad Rishmany ${ }^{\dagger}$ \\ Issam Tawk ${ }^{t}$ \\ Michel Daaboul
}

Energy efficiency of car body structures includes, in addition to the obvious aspect of fuel consumption, an ultra-high level of passenger safety. However, with traditional manufacturing processes, an acceptable level of passenger safety results in an increased car body weight. The realization of ultra-high strength properties and, at the same time, improved structural weight could be achieved through different tailoring routes such as: Tailor-Rolling, Tailor-Welding, and differential thermomechanical processes. In this technological context, an FE model is developed for the improvement of tailored-rolled technology through which an optimization of state of the art thickness can be realized by using different high-strength materials in the proposed FE model of an existing A-Pillar geometry.

Keywords: Automotive, FEA, Metal Forming, Nonlinear Analysis, Tailoring.

\section{Introduction}

Each passing year, car crashes end the life of millions around the globe. Hence, passenger safety is of continuous essential concern. Stricter traffic laws might lead to fewer casualties by decreasing the number of vehicle collisions. However, with the yearly increase of the number of vehicles on the streets, accidents remain frequent and cannot be completely prevented. For this purpose, governments around the world are increasing their vehicles safety requirements. Beside front and side crashes, the rollover crash is one of the most frequent crashes leading to fatal results. Hence the importance of car structural components, such as A-pillars, B-pillars and door beams to protect passengers during a crash. Considering various constraints such as vehicle weight, cost, fuel consumption, and process complexity, recent developments focus on altering the properties of car components to increase their strength without adding additional weight. Therefore, tailoring technology is employed to produce parts with application oriented properties adapted to variable load profiles, such as high strength for high load locations and ductility for joining sections (Gresser, 2014). In this work, tailor rolling of an A-Pillar is conducted in a rollover crash situation to determine a suitable material with an optimized

\footnotetext{
* Assistant Professor, University of Balamand, Lebanon.

${ }^{\dagger}$ Assistant Professor, University of Balamand, Lebanon.

* Associate Professor, University of Balamand, Lebanon.

Associate Professor, University of Balamand, Lebanon.
} 
thickness profile combining both aspects of increased safety and reduced weight.

A- Pillars hold either side of the windshield set up but their essential function is ensuring passenger's safety during a rollover crash (National Highway Traffic Safety Administration, 2006). Depending on the load profile during an accident, differential properties distribution is required.

\section{Tailoring Technology}

An important technology trend is the production of parts with "tailored" properties. This technique allows the adaptation of material properties and/or thickness to the loading profile of the final part (Steinhoff et al., 2009). Tailoring has a wide range of application but has mostly grown in the automotive industry due to the advantages that set it apart from other conventional methods. Tailored-rolled blanks, tailored-welded blanks and differential thermo-mechanical processes constitute the different tailoring techniques leading to a differential properties distribution.

\section{Tailor Rolled Blanks}

The first attempts to use blanks with higher thickness only in areas where high loads are expected were done over 30 years ago. Tailored rolling consists of differentiating the thickness profile of metal sheets in the rolling process (Figure 1). These sheets with longitudinal thickness transitions are produced by a controlled online adjustment of the roll gap. This process route aims in setting increased thickness in heavily loaded zones that leads to a reduction of an undesired plastic deformation which ensures passenger safety. On the other hand, the decreased thickness of end zones (Figure 1) leads to increased ductility which results in a desired increase in energy absorption. The application of Tailor Rolled Blanks can be found in different structural components e.g. pillars, beams and vehicle front end for frontal impact (Hauger and Kopp, 1995; Hirt et al., 2005; Duan et al., 2016).

Figure 1. Tailor Rolling Process (Hillmann, 2012)

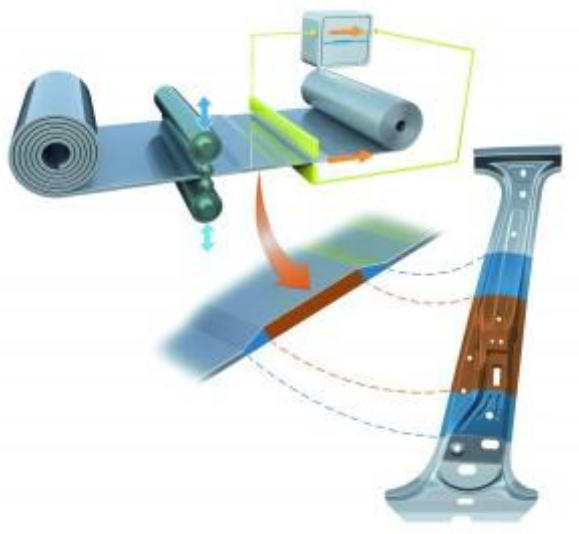


Since 2006 different car manufacturers e.g. among others BMW, Mercedes, Volkswagen, Volvo and Ford are integrating Tailor Rolled Blanks (TRBs) in press hardening process (Figure 2) (Schrek et al., 2016).

Figure 2. Press Hardening Process of Tailor Rolled Blanks (Schrek et al., 2016)

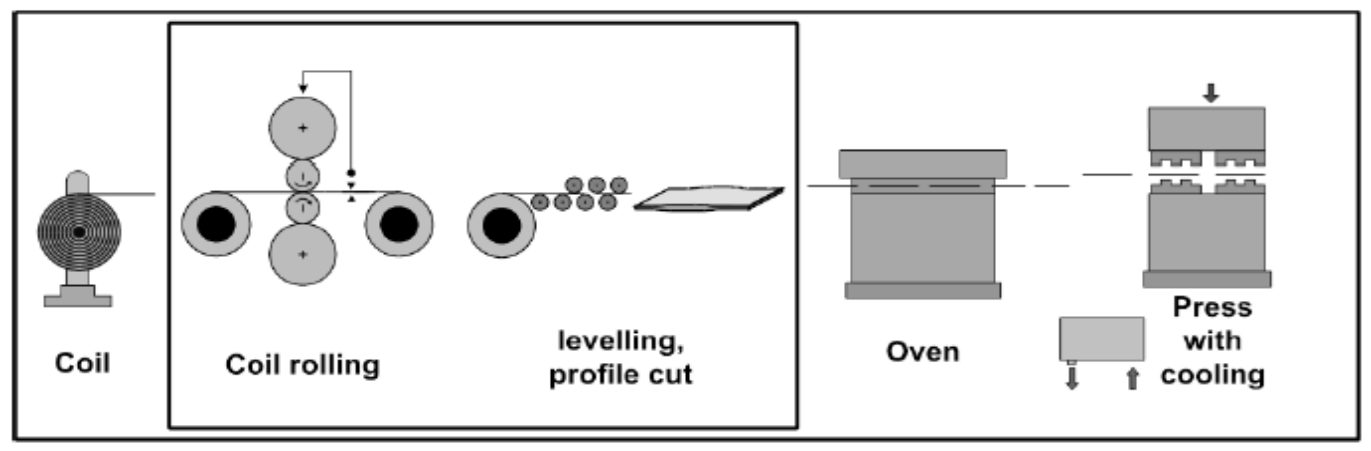

\section{Tailor Welded Blanks}

In this process route, laser welding is used to join different types of metals of different mechanical properties, thicknesses and coatings (figure 3). This allows ultra-high strength in heavily loaded zones without any significant weight increase (Schrek et al., 2016; Karbasian, et al., 2010).

Figure 3. Tailor Welded B-Pillar (Arcelormittal, 2016)
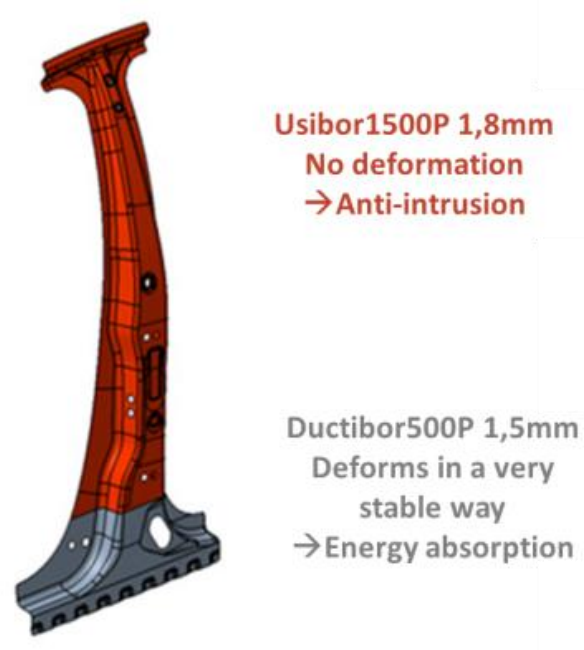

Tailored welded blanks consisting of heat treatable and non-heat treatable steel grades can be included also in a press hardening process (Figure 4). This allows also the production of parts with tailored properties. Because of the martensitic transformation in the heat-treatable steel, the final part strength increases contrary to that of the non-heat-treatable steel. Before laser welding of the blanks, the coating of the weld zone must be removed. The limited formability during hot forming and the position of the weld seam are of high 
importance in the process design (Karbasian, et al., 2010; Maikranz-Valentin et al., 2008; Steinhoff et al., 2009; Deinzer et al., 2008).

Figure 4. Audi A4 Body-in-White with Tailor Welded and Press Hardened BPillar

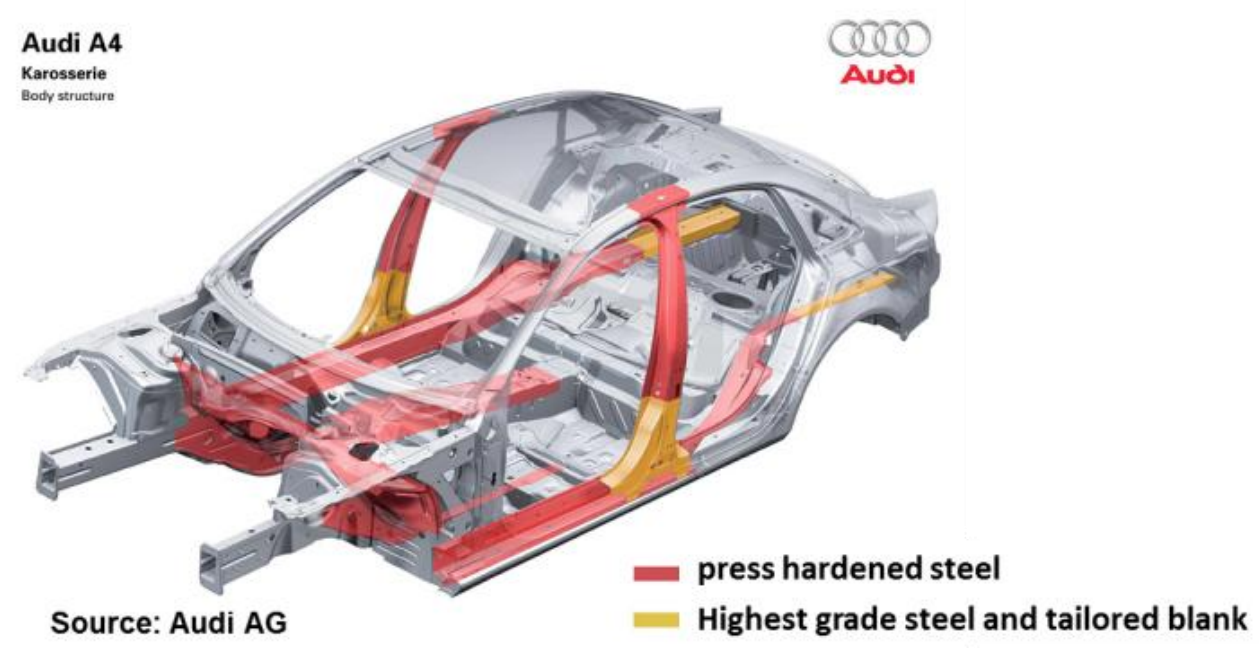

Differential Thermo-Mechanical Treatment

The advanced route to produce tailored parts can be achieved by a differential thermo-mechanical process treatment where differential heating and cooling strategies are applied leading to different microstructural zones. Figures 5 and 6 show that the translation of crash load situations leads to a differential properties profile. The characteristic loading profile for typical crash situations makes clear that locally varying properties adapted to the component specific load profile would be of essential importance regarding passenger safety (Maikranz-Valentin et al., 2008; Steinhoff et al., 2009).

Figure 5. Load Path for Frontal and Side Impacts (Pfestorf, 2016)
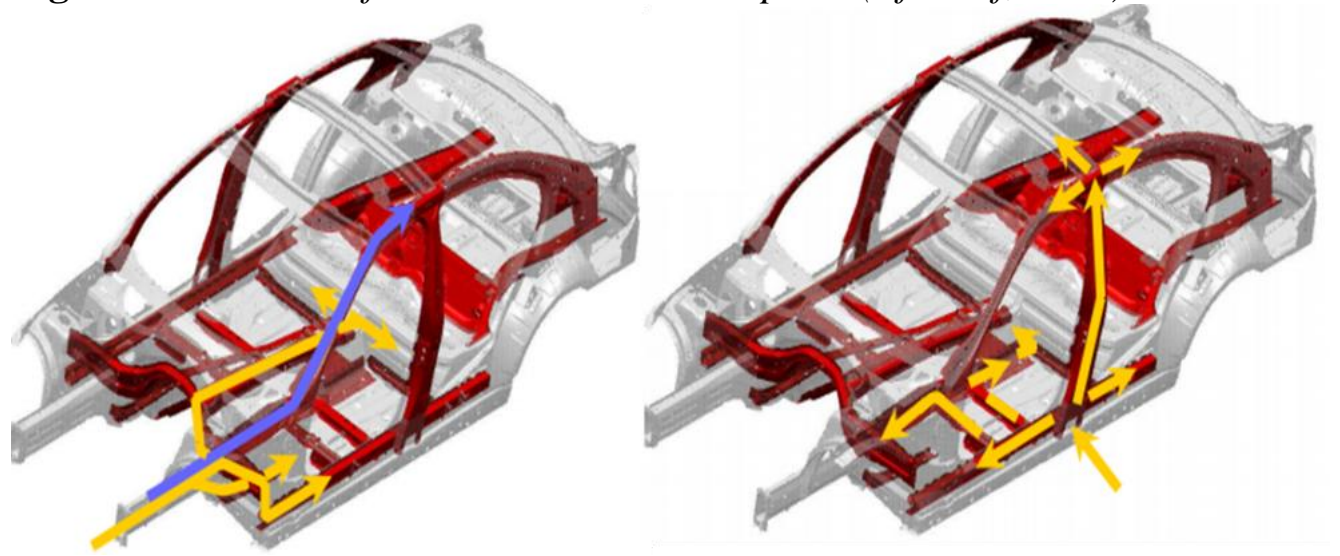
Figure 6. Tailored Property Profile a B-Pillar (Maikranz-Valentin et al., 2008)

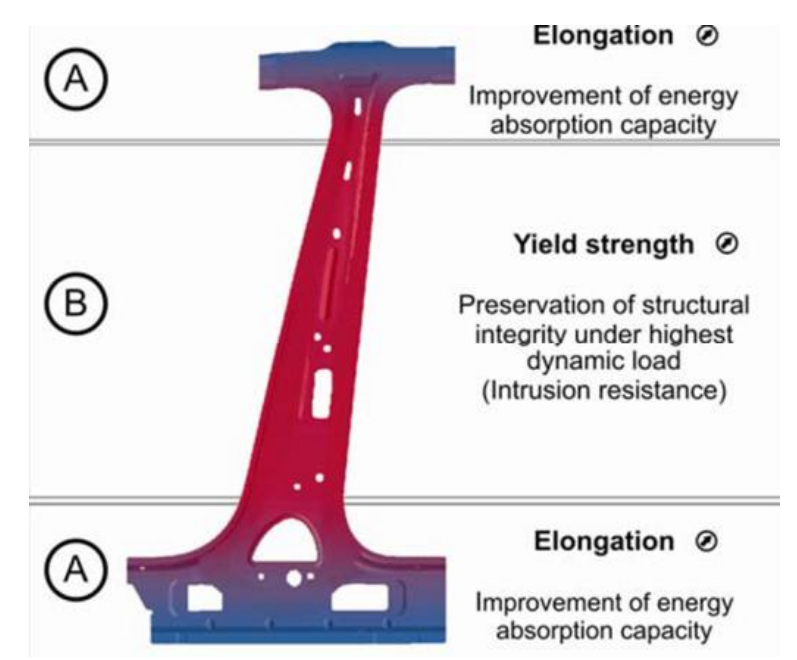

Among others, an advantage of thermo-mechanical processes is a decisive reduction in the process chain which leads to reduced process time and cost. On one hand, this process route increases the complexity of forming process due to limited know-how, scaling and high energy consumption (PerezSantiago et al., 2013; Maikranz-Valentin et al., 2008; Skilliter, 2016). On the other hand, among the several advantages of this process are the complex geometries that could be achieved (high formability), ultra-high strength and consequently reduced weight due to low thicknesses (Rehse, 2006).

A typical example of employing differential heat treatment is Press Hardening which combines forming and heat treatment of the sheet metal component in a single process step (Neugebauer, 2012). The general press hardening process consists of heating the high performance metal sheets (22MnB5) in the furnace to temperatures above $900{ }^{\circ} \mathrm{C}$ (Ac3) followed by an in-die hardening (Figures 7,8) that allow the martensitic transformation (Wang $\mathrm{Z}$ et al., 2014).

Figure 7. The Process Chain of Press Hardening (Industrial-lasers, 2016)

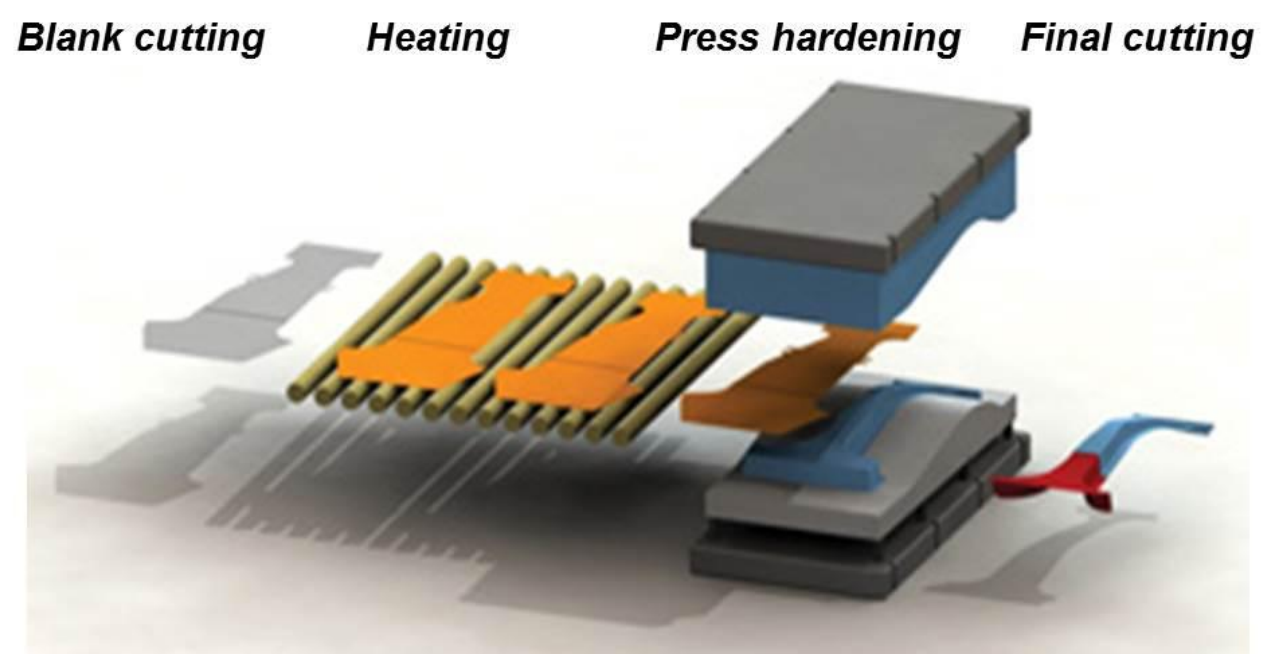


Figure 8. Production of Complex Structural Components with Integrated Hardening (Maikranz-Valentin et al., 2008)

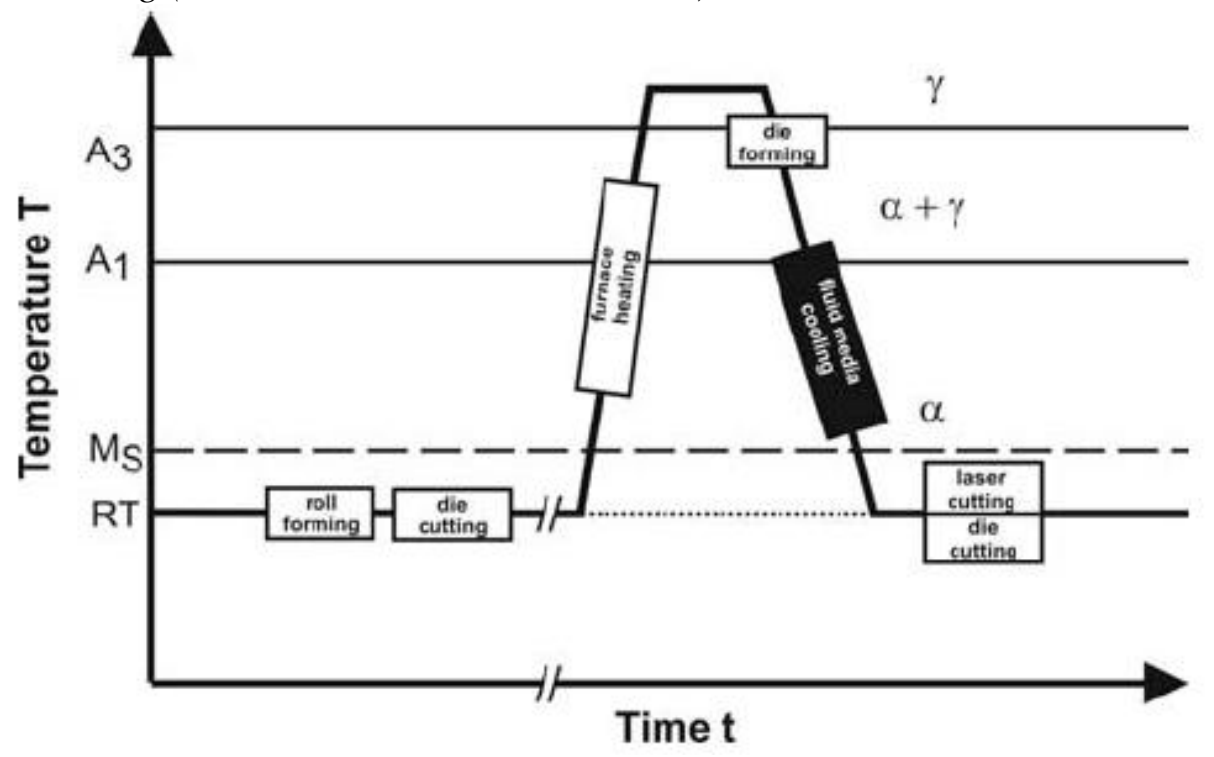

Beside the significant advantages of using the press hardening process, different challenges must be handled when it comes to die design and manufacturing as well as press deformation during the forming process.

Currently, the use of advanced high-strength steels (AHSS) in car body parts results in a higher proportion of harder surfaces on the working area of the forming dies as well as long try-out iterations, due to their great springback. Therefore, tempered surfaces and insert blocks harder than 60 HRC are needed to withstand the forming loads with an acceptable service life expectation (Lopez de Lacalle et al., 2006). Another problem to be faced by die manufacturers is the occurring of errors coming from die deformation due to their asymmetrical shape. These deformations are relatively small compared to die size but can become bigger than the allowed tolerance for the final produced part. In this context, different approaches were proposed e.g. design and control of variable binder force for stamping dies, springback compensation, the use of newly developed utilities in the preparation stage and the elaboration of CNC programs using CAM software, a knowledge-based system for intelligent stamping process planning and an intelligent feature based DFS (design for stamping) system for implementing the stampability evaluation (Lopez de Lacalle et al., 2006; Cao et al., 2001; Lingbeek et al., 2005; Dequan et al., 2006; Tang et al., 2001).

\section{Materials}

Nowadays, many materials and especially steel alloys are available for the production of A-Pillars covering a range from High- to Ultra-High strength. In this context, high grade Dual Phase steels, TRIP, martensitic steel and hot formed 22MnB5 are to be mentioned (Rehse, 2006; Leiber, 2016). In addition 
to strength and toughness values of the final part, other mechanical properties of these materials (e.g. ductility) are of high importance especially when it comes to forming process.

Figure 9. Advanced High Strength Steels (AHSS), Elongation vs. Total Tensile Strength of Various Materials (Skilliter, 2016)

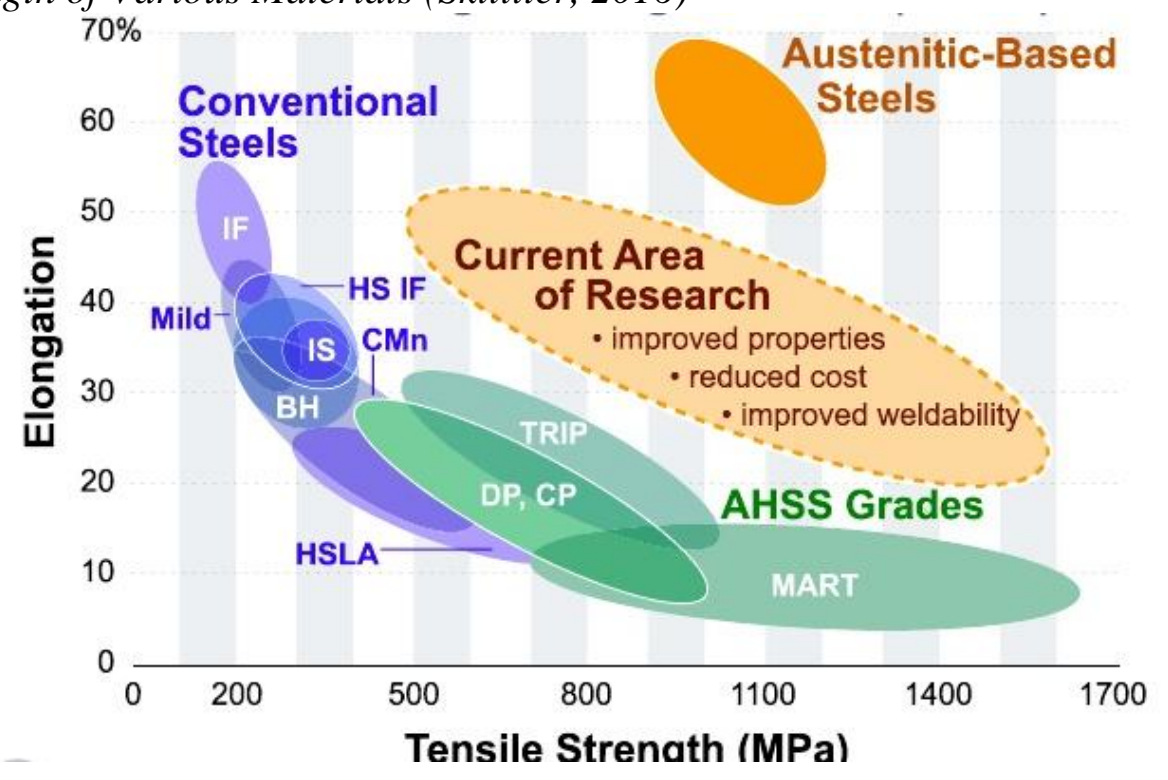

For conventional materials, a strength increase leads to a decrease in ductility and vice-versa. However, developed materials such as TRIP, TRIP XP and TWIP offer a combination of both high strength and ductility (Figure 9). Table 1 shows the materials adopted for the present study with their mechanical properties.

Table 1. Mechanical Properties of Materials used in this Study

\begin{tabular}{|l|l|l|l|}
\hline Material & $\mathbf{D P}-500$ & TRIP-780 & MS-1300 \\
\hline Yield Stress (MPa) & 310 & 505 & 1156 \\
\hline Yield Strain (\%) & 0.001 & 0.001 & 0.001 \\
\hline Ultimate Stress (MPa) & 528 & 793 & 1355 \\
\hline Ultimate Strain (\%) & 18.90 & 23.90 & 3.20 \\
\hline Elasticity Modulus (Pa) & $210 \mathrm{E}+9$ & $210 \mathrm{E}+9$ & $210 \mathrm{E}+9$ \\
\hline Plastic Modulus (Pa) & $1.1535 \mathrm{E}+09$ & $1.2051 \mathrm{E}+09$ & $6.2207 \mathrm{E}+09$ \\
\hline
\end{tabular}

Due to the absence of stress-strain data, a bilinear behavior law was adopted for all materials in which stress is assumed to vary linearly between the yield strength and ultimate strength (Figure10). The slope of the inelastic region was found using the secant method. 
Figure 10. Stress-Strain Diagram with Bilinear Behavior Assumed for Presented Materials

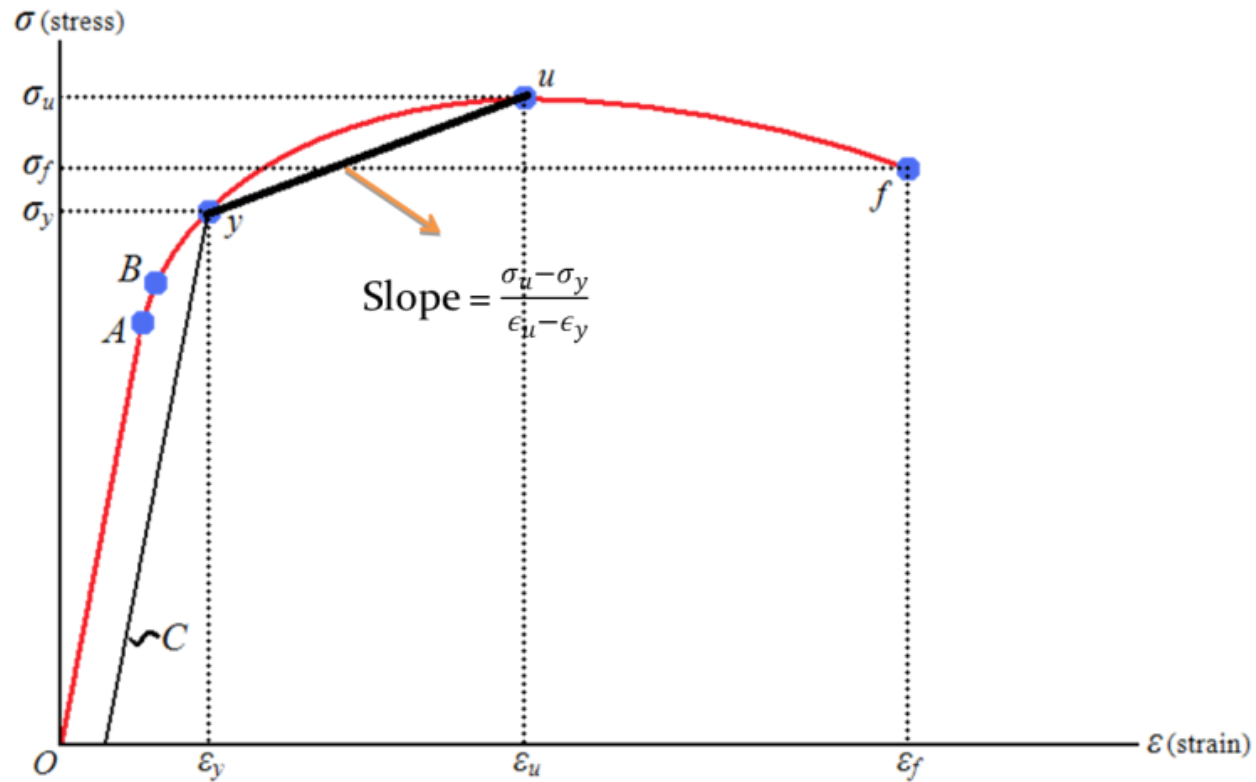

\section{Finite Element Modeling}

A typical B-Pillar geometry is considered in this study (Figure 12). Due to the low thickness of the B-Pillar, 2D shell elements were employed. The finite element analysis was conducted using MSC SimXpert 2013. An advantageous feature of SimXpert is the possibility of introducing a variable shell thickness which simplifies the optimization task.

\section{Loads and Boundary Conditions}

$\underline{\text { Load }}$

In this work, the case of a rollover crash is investigated. For this purpose, the Federal Motor Vehicle Safety Standards (FMVSS: No 216) is adopted (Figure 11) (National Highway Traffic Safety Administration, 2006). 
Figure 11. Loading Device Location and Application to the Roof (National Highway Traffic Safety Administration, 2006)

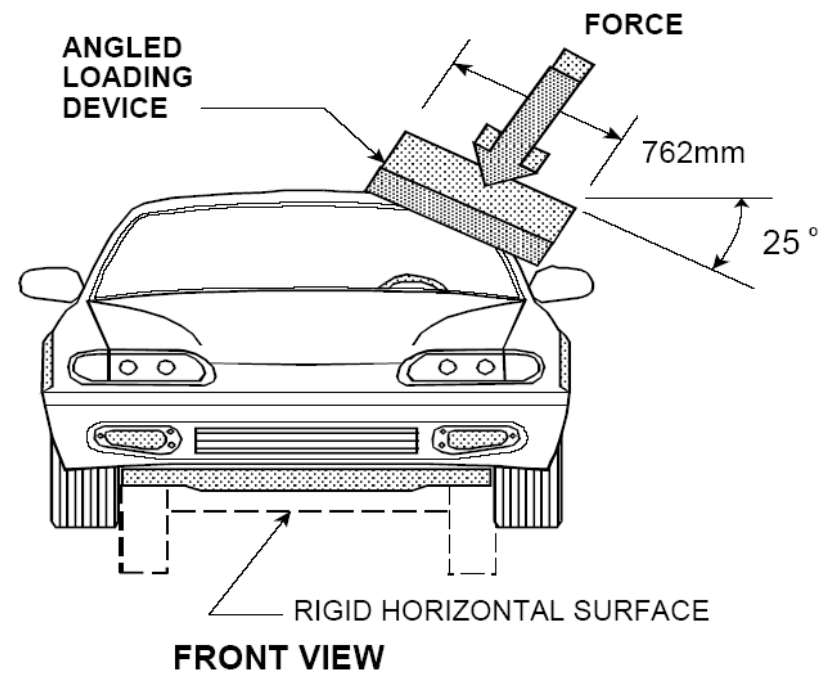

The crash test following FMVSS 216 standard is applied under these conditions:

The Vehicle has a mass of $2224 \mathrm{Kg}$. A car roof withstands a load of 1.5 times the unloaded vehicle's weight (Karbasian et al., 2010). With a safety factor equal to $10 \%$, a total force of $36 \mathrm{KN}$ is obtained. The A-pillar holds about $12.5 \%$ from the total load $(4.5 \mathrm{KN})$.

\section{$\underline{\text { Supports }}$}

The A-Pillar is assumed to be fixed at one edge and free to displace at the other edge (cantilever). This condition is considered conservative since it results in higher stresses and deformation compared to the real configuration.

Figure 12. FE Model and Dimensions of a Typical A-Pillar

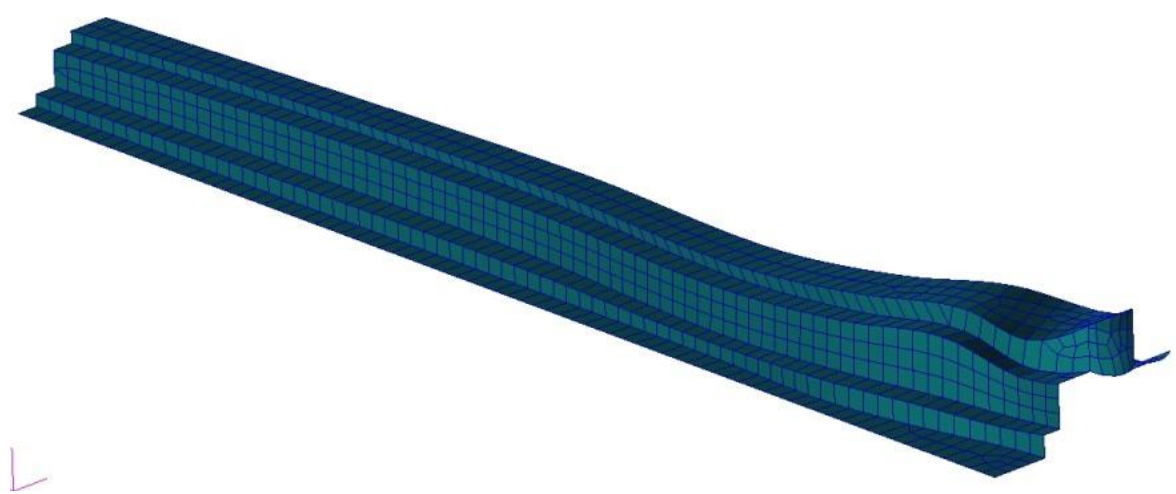

\section{Meshing}

An appropriate element size is essential for minimizing simulation time without sacrificing results accuracy. For this purpose, prior to nonlinear 
analysis, a linear static analysis was conducted using linear quadrilateral elements. The analysis was carried out under the same loading conditions previously set and the maximum displacement and stress in the structure were recorded. The element size was reduced gradually until a negligible variation of stress and displacement results occurred.

Finally, an average element size of $10 \mathrm{~mm}$ was adopted resulting in a total of 1138 elements and 1230 nodes (Figure 12).

\section{Failure Criteria}

Two failure criteria were adopted: the Von Mises stress criteria (Von Mises $\leq$ Ultimate stress) and maximum deflection criteria. It is to note here that the maximum displacement of the roof structure must be kept below $127 \mathrm{~mm}$ to ensure the occupants safety.

An optimized thickness profile is to be set for each material (Table 1) satisfying both criteria. This is achieved by reducing the thickness gradually until one of the failure criteria is reached.

Simulations were conducted using the General Non-Linear structural analysis module of SimXpert (SOL400, large displacement and follower force) with a fixed time stepping, a total of 10 steps, a time step of 0.1 and a maximum of 10 increments during each iteration.

\section{Results}

Due to similarity in behavior for the different materials, stress and displacement results for Dual Phase 500 steel are presented for an A-Pillar with a uniform thickness of $3.51 \mathrm{~mm}$. For this thickness, both failure criteria are satisfied (maximum von Mises stress $=328.41 \mathrm{MPa}$, maximum deflection $=96$ $\mathrm{mm}$ ) as shown in figures $13 \mathrm{a}$ and 14 a respectively. Resulting factors of safety are 1.60 and 1.32 for stress and displacement respectively.

Results show that maximum stresses are distributed and become lower towards the loaded zone. This can be explained by the high energy absorption capacity due to high displacement obtained in the loaded zone (Figure 14a and 14b). Consequently, the desired weight reduction could be obtained by decreasing the thickness of these zones. However, this thickness reduction is limited due to geometrical interaction between loaded and unloaded zones which results in even higher values of displacement (maximum von Mises stress = 326.16 MPa, maximum deflection $=118.5 \mathrm{~mm}$ ) in the loaded zone (figures $13 \mathrm{~b}$ and 14b). Resulting factors of safety are 1.62 and 1.07. The mass obtained before optimization is $3.46 \mathrm{Kg}$. 
Figure 13. Von-Mises Stress Distribution (MPa) a) Uniform Thickness Profile and b) Optimized Thickness Profile

(a)

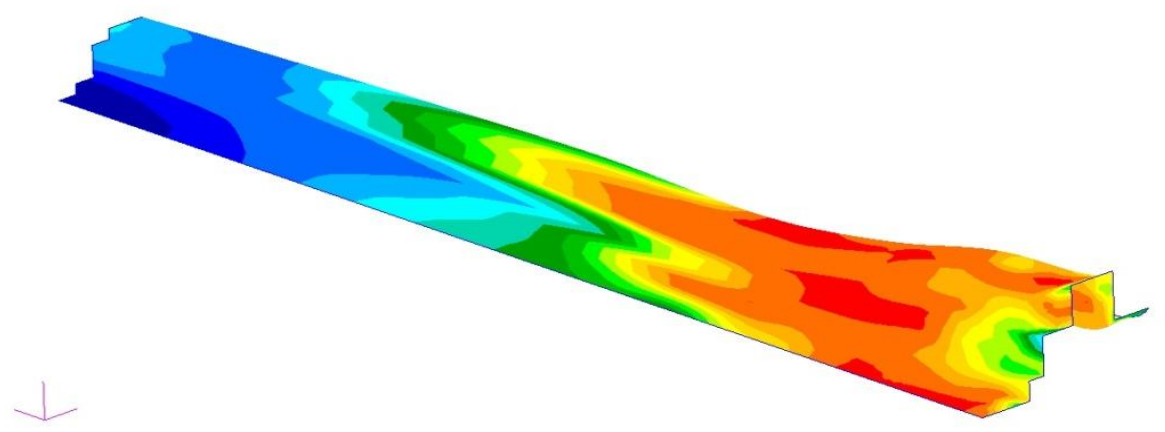

(b)
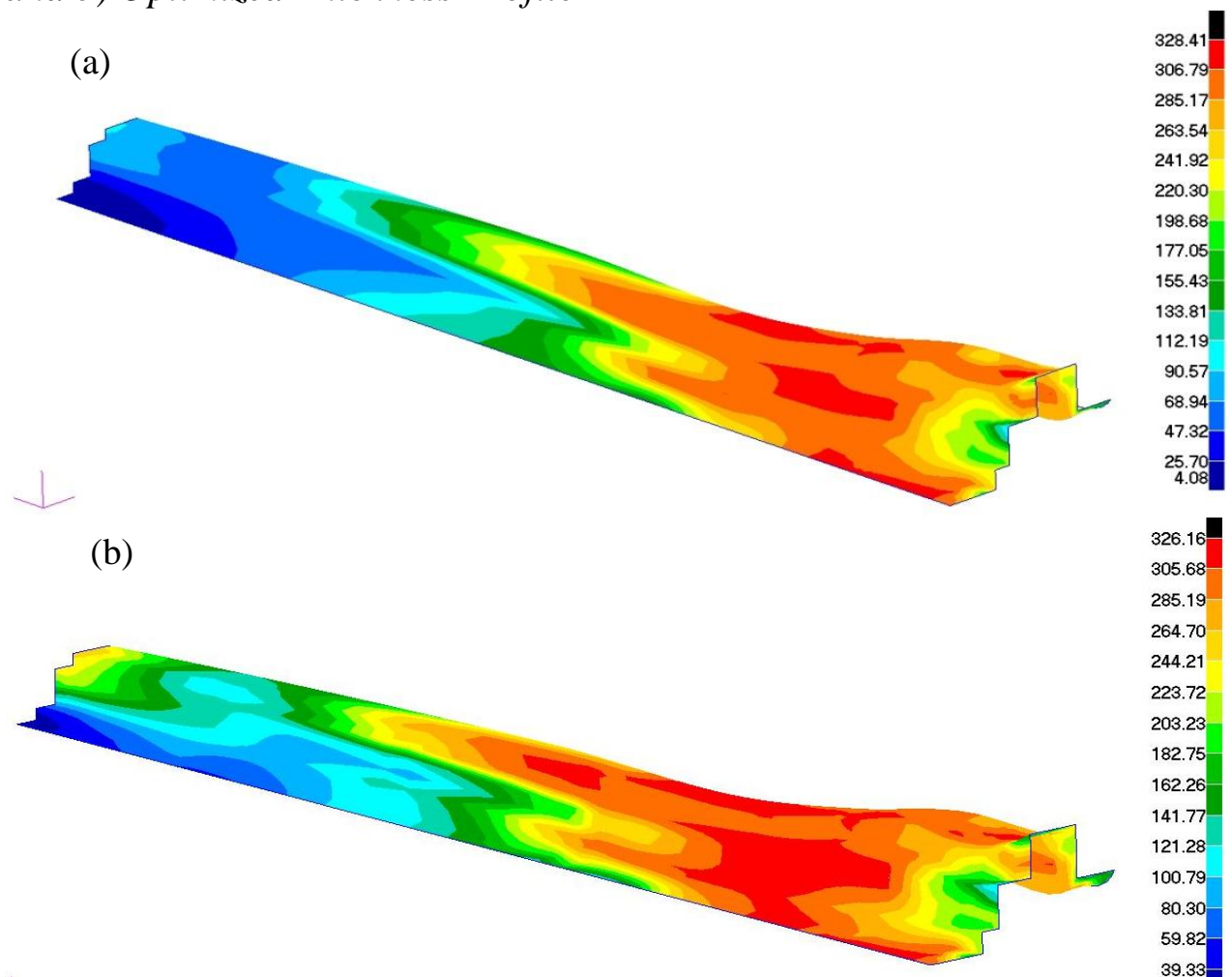

) 326.16

326.16 285.19 264.70 244.21 223.72 203.23
182.75 162.26 141.77 121.28 100.79
80.30

Figure 14. Displacement Results a) Uniform Thickness Profile and b) Optimized Thickness Profile

(a)

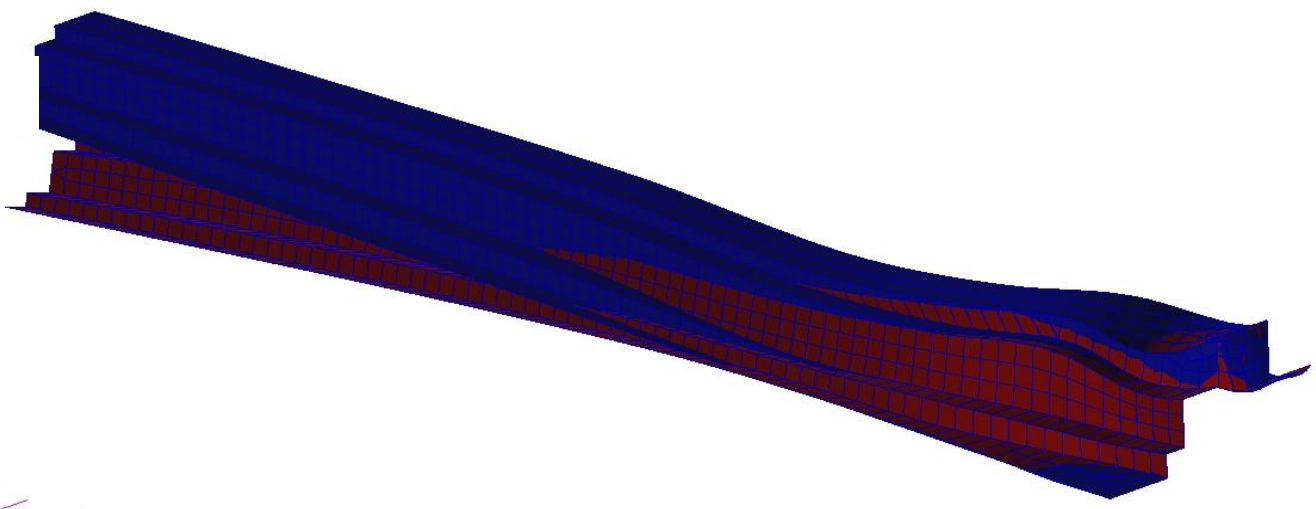

(b)

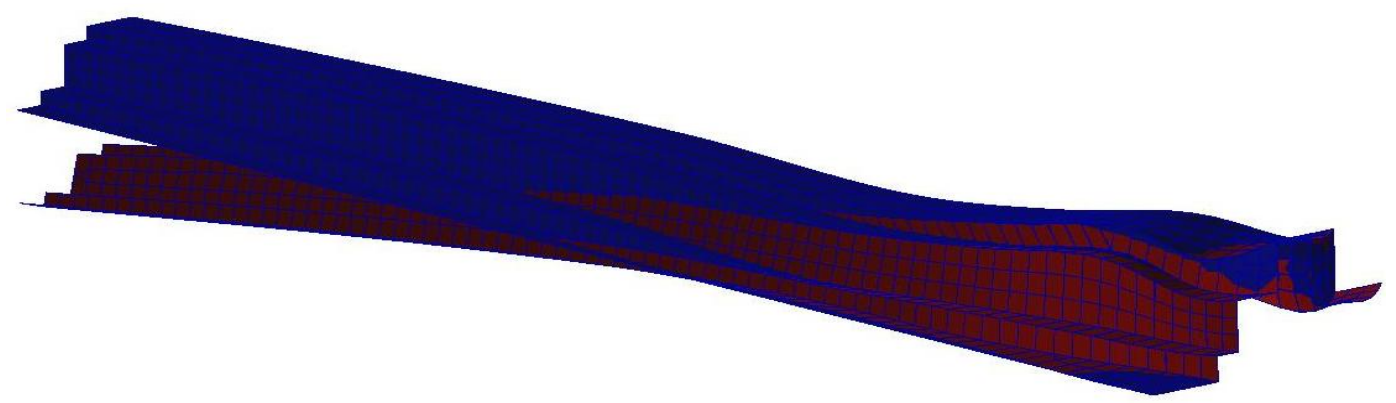


As seen in Figure 15, the resulting thickness profile maintains a value of $3.85 \mathrm{~mm}$ in the zone of maximum stress and decreases gradually towards zones with maximum displacement reaching a minimum value of $1.30 \mathrm{~mm}$. The mass obtained after optimization is $2.76 \mathrm{Kg}$ which implies a $20 \%$ mass reduction compared to uniform thickness. It is to note here that due to the high ductility of this material, the limit for displacement was reached at a relatively low stress value.

Figure 15. Dual Phase Steel Thickness Profile ( $\mathrm{mm})$

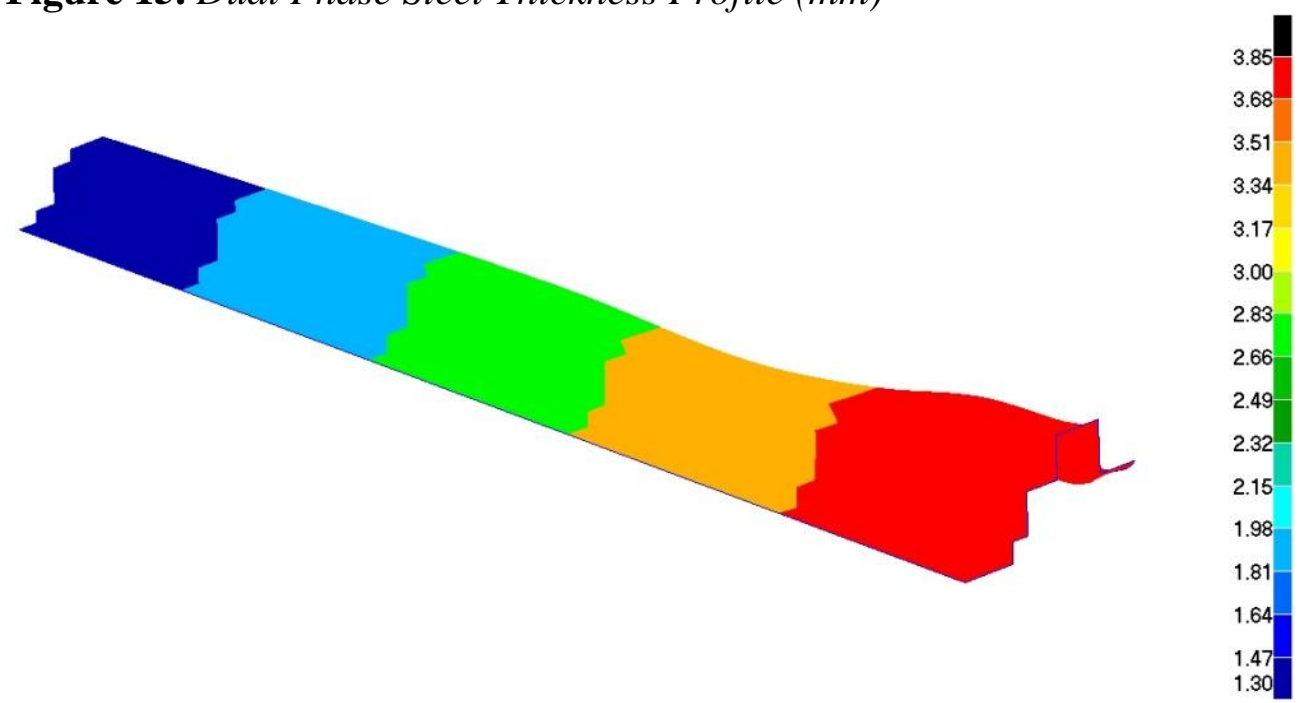

Similar to the results obtained for the dual phase, the thickness profile of the A-Pillar made of MS-1300 steel could be reduced from $2.8 \mathrm{~mm}$ in the zone with maximum stress values to $0.9 \mathrm{~mm}$ in the zone with minimum stress values (Figure 16). Due to the high strength of this material, the limit for stress and displacement could be nearly reached. The reduction of the thickness profile has led here to a mass decrease from $2.237 \mathrm{Kg}$ to $1.88 \mathrm{Kg}$ leading to a mass reduction of $16 \%$.

Figure 16. MS-1300 Steel Optimized Thickness Profile (mm)

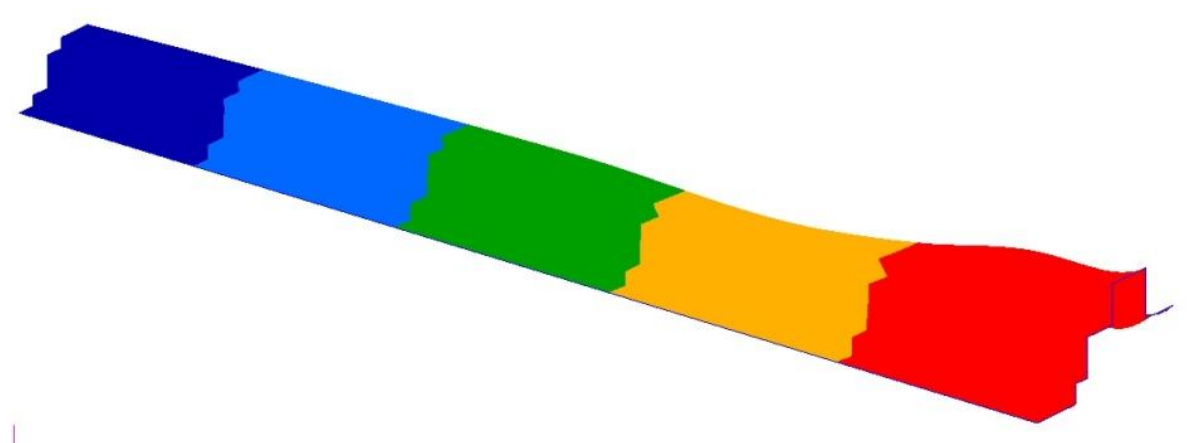


The obtained thickness profile for TRIP-780 ranges from $3.1 \mathrm{~mm}$ in the zone with maximum stress values to $1 \mathrm{~mm}$ in the zone with minimum stress values (Figure 17). Similar to the results of DP steel, due to the high ductility of this material, the high displacement was reached at a relatively low stress value. This explains the factors of safety of 1.53 and 1.21 for stress and displacement respectively. The mass is reduced from $2.76 \mathrm{~kg}$ to $2.19 \mathrm{~kg}$ leading to a mass reduction of $21 \%$.

Figure 17. TRIP-780 Steel Optimized Thickness Profile (mm)

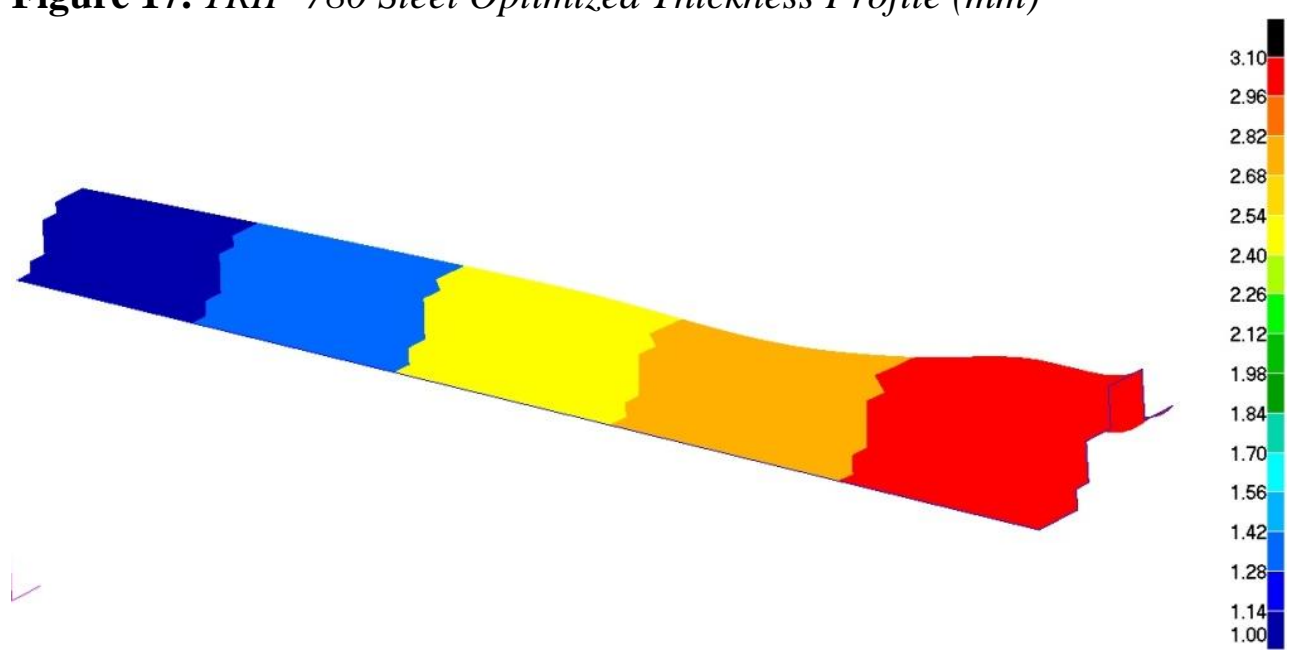

Table 2 summarizes factors of safety and weight values of the A-pillar for the different materials tested.

Table 2. Summary of results for different materials

\begin{tabular}{|c|c|c|c|c|}
\hline Material & $\begin{array}{c}\text { Weight (uniform } \\
\text { thickness) }(\mathrm{kg})\end{array}$ & $\begin{array}{c}\text { Weight (optimized } \\
\text { thickness) }(\mathrm{kg})\end{array}$ & $\begin{array}{c}\text { Factor of } \\
\text { safety } \\
\text { (stress) }\end{array}$ & $\begin{array}{c}\text { Factor of } \\
\text { safety } \\
\text { (displacement) }\end{array}$ \\
\hline $\begin{array}{c}\text { Dual } \\
\text { Phase }\end{array}$ & 3.46 & 2.76 & 1.62 & 1.07 \\
\hline TRIP & 2.76 & 2.19 & 1.53 & 1.21 \\
\hline MS & 2.24 & 1.88 & 1.17 & 1.11 \\
\hline
\end{tabular}

\section{Conclusions}

Nowadays, the main focus in car body development is concentrated on increasing passenger safety and decreasing the weight which results in high fuel efficiency and reduced emissions. In this context, tailor rolling technology was employed in a nonlinear elasto-plastic FE Model for the B-pillar, which is a representative structural component of the car chassis.

For this purpose, three different materials (Dual Phase steel, Trip steel and MS steel) were investigated. Loads and boundary conditions were applied in order to simulate a rollover crash following the FMVSS 216 standard. The analysis resulted in an optimized thickness profile for each material. A 
comparison between the constant thickness profile and the optimized profile for each material shows a reduction of $20 \%, 21 \%$, and $16 \%$ for the Dual Phase, Trip and MS respectively. Compared to each other, MS steel offers the lowest weight followed by TRIP and finally the Dual Phase. This result is primarily attributed to the mechanical and physical properties of each material (strength, ductility and density). Minimum thickness values were obtained with MS due to its ultra-high strength.

With the continuous development of manufacturing processes and materials, better results in terms of safety and weight could be further obtained. In this prospect, differential thermo-mechanical processes offer several advantages in comparison to tailor welding and tailor rolling techniques. However, the complexity of this process limits its application on a larger scale.

\section{References}

Arcelormittal, (2016). "Hot Stamped B-pillar solution". http://bit.ly/2gO0ucl.

Cao J, Kinsey B, Yao H, Viswanathan V, Song N, (2001). "Next generation stamping dies-controllability and flexibility". Robot CIM-Int Manuf 17:49-56.

Deinzer G et al., (2008). "Presshärten von Tailor Welded Blanks" [Press Hardening of Tailor Welded Blanks]. Werkstoffauswahl, Eigenscahften und Verbindungstechnik. In Merklein, M. (Edtr.): 3. Erlanger Workshop Warmblechumformung. Meisenbach Verlag Bamberg, Erlangen, pp. 1-22.

Dequan Y, Rui Z, Jun Ch, Zhen Z, (2006). "Research of knowledge based system for stamping process planning". Int J Adv Manuf Technol 29:663-669.

Duan L et al., (2016). "Crashworthiness design of vehicle structure with tailor rolled blank". Struct Multidisc Optim 53:321-338.

Gresser, E. (2014). "Traffic accidents kill 1.24 million people a year worldwide; wars and murders, 0.44 million". Progressive-Economy.

Hauger A.; Kopp R., (1995). "Kinematische Erzeugung von belastungsangepassten Langprodukten mit einem über Länge variablen Querschnitt mittels Walzen" [Kinematic generation of load-adapted long products with a variable cross-section by means of rollers]. Abschlusskolloquium zum DFG Schwerpunktprogramm Flexible Umformtechnik, Verlag Mainz, Aachen.

Hillmann J, (2012). "The new Golf VII - Lightweight Design in Large Scale Production". Fachvortrag Aachener Karosserietage.

Hirt G, Abratis C, Ames J, Meyer A, (2005). "Manufacturing of Sheet Metal Parts From Tailor Rolled Blanks". Journal for Technology of Plasticity, Vol. 30, Number 1-2.

Karbasian H, \& Tekkaya A. E, (2010). "A review on hot stamping”. Journal of Materials Processing Technology, 210(15), 2103-2118.

Leiber, (2016). "Spezielle Anwendungen von Aluminium-Legierungen sowie Festigkeits-Eigenschaften für die jeweils definierten Prüfrichtungen L oder T" [Special applications of aluminum alloys as well as strength properties for the defined test directions L or T]. WERKSTOFFDATENBLATT.

Lingbeek R, Huétink J, Ohnimus S, Petzoldt M, Weiher J, (2005). "The development of a finite elements based springback compensation tool for sheet metal products". J Mater Process Technol 169:115-125. 
Lopez de Lacalle L. N. et al., (2006). "Improving the high-speed finishing of forming tools for advanced high-strength steels (AHSS)". The International Journal of Advanced Manufacturing Technology, Volume 29, Issue 1, pp 49-63.

Maikranz-Valentin M et al., (2008). "Components with Optimised Properties due to Advanced Thermo-mechanical Process Strategies in Hot Sheet Metal Forming". Steel research int. 79 No. 2.

National Highway Traffic Safety Administration, (November 16, 2006). "Laboratory Test Procedure for FMVSS 216 Roof Crush Resistance". TP-216-05.

Neugebauer R, Schieck F, Polster S, Mosel A, Rautenstrauch A, Schoenherr J, Pierschel N, (2012). "Press hardening - An Innovative and Challenging Technology". Archives of Civil and Mechanical Engineering, 12(2), 113-118.

Perez-Santiago R, et al., (2013). "Hot Stamping a B-Pillar with Tailored Properties: Experiments and Preliminary Simulation Results". 4th International Conference HOT SHEET METAL FORMING of HIGH-PERFORMANCE STEEL CHS2; June 9-12, 2013, Luleå, Sweden.

Pfestorf M, (2016). "The Application of Multiphase Steel in the Body-in-White". In: Great Design in Steel Seminar. www.autosteel.org.

Rehse M, (2006). "Flexible Rolling of Tailor Rolled Blanks", presented at Great Designs in Steel, March $8^{\text {th }}$. Livonia, MI, USA: Steel Market Development Institute.

Schrek A, Svec P, Gajdosova V, (2016). "Deformation Properties of Tailor-Welded Blank Made of Dual Phase Steels". In DE GRUYTER, DOI 10.1515/ama-2016-0007.

Skilliter M, (2016). "Tailored coils - A new process to further expand tailored applications". www.Autosteel.org.

Steinhoff K.; Saba N.; Maikranz-Valentin M.; Weidig U., (2009). "Optimized Processes and Products in Hot Sheet Metal Forming”. In: Oldenburg, M.; Steinhoff, K.; Prakash, B. (Edtrs.): Proceedings of the $2^{\text {nd }}$ International Conference on Hot Sheet Metal forming of High-Performance Steel, Auerbach (D): Verlag Wissenschaftliche Skripten, pp. 29-42.

Tang DB, Zheng L, Li ZZ, (2001). "An intelligent feature-based design for stamping system”. Int J Adv Manuf Technol 18:193-200.

Wang Z et al., (2014). "Hot Stamping of high Strength Steel with Tailored Properties by two Methods". Procedia Engineering 81, 1725-1730. 
